\title{
Woody biomass production lags stem-girth increase by over one month in coniferous forests
}

\author{
Henri E. Cuny et al.*
}

\begin{abstract}
Wood is the main terrestrial biotic reservoir for long-term carbon sequestration ${ }^{1}$, and its formation in trees consumes around $15 \%$ of anthropogenic carbon dioxide emissions each year $^{2}$. However, the seasonal dynamics of woody biomass production cannot be quantified from eddy covariance or satellite observations. As such, our understanding of this key carbon cycle component, and its sensitivity to climate, remains limited. Here, we present high-resolution cellular based measurements of wood formation dynamics in three coniferous forest sites in northeastern France, performed over a period of 3 years. We show that stem woody biomass production lags behind stem-girth increase by over 1 month. We also analyse more general phenological observations of xylem tissue formation in Northern Hemisphere forests and find similar time lags in boreal, temperate, subalpine and Mediterranean forests. These time lags question the extension of the equivalence between stem size increase and woody biomass production to intra-annual time scales ${ }^{3-6}$. They also suggest that these two growth processes exhibit differential sensitivities to local environmental conditions. Indeed, in the wellwatered French sites the seasonal dynamics of stem-girth increase matched the photoperiod cycle, whereas those of woody biomass production closely followed the seasonal course of temperature. We suggest that forecasted changes in the annual cycle of climatic factors ${ }^{7}$ may shift the phase timing of stem size increase and woody biomass production in the future.
\end{abstract}

The atmospheric carbon dioxide concentration undergoes a seasonal cycle in the Northern Hemisphere with a 6-19 p.p.m. amplitude $^{8}$, thereby representing intra-annual net fluxes greater than annual anthropogenic emissions. This cycle is predominantly driven by the annual rhythm of terrestrial plant activity, including the balance between carbon assimilation by photosynthesis, release by respiration and sequestration through biomass formation. Wood formation is the primary biological process through which carbon is durably sequestered in woody plants, and is thus a major contributor to the net forest carbon sink of about 2.5 petagrams of carbon per year that mitigates climate change ${ }^{2}$. However, large uncertainties remain in the response of the global carbon cycle to continuing climate change ${ }^{9}$. For example, increased seasonal amplitudes in the Northern Hemisphere carbon dioxide concentration over the last decades suggest large ecological changes in northern forests and a major shift in the global carbon cycle ${ }^{8}$. In situ observations are required to better identify the intraannual dynamics of the biological processes controlling carbon cycling in terrestrial ecosystems, and to accurately quantify their influence on the global carbon budget.

Since the late 1990s, 'eddy covariance' measurements have emerged as the primary technique to evaluate net carbon fluxes between a forest canopy and the atmosphere, from sub-hourly to yearly time scales ${ }^{10}$. Inside a forest ecosystem, carbon allocation among the different biomass components (for example leaves, stems, roots, soil) can be estimated using repeated inventories ${ }^{3}$, including measurements of tree size changes ${ }^{4}$ and litter fall ${ }^{11}$, and/ or assessment from phenocams ${ }^{12}$ or remote sensing ${ }^{13}$. At fine time scales, joint assessments of carbon fluxes in forest ecosystems using eddy covariance and tree size measurements often do not yield compatible perspectives on intra-annual ecosystem carbon dynamics $^{14,15}$. This is not surprising, as none of these methods allow a direct quantification of when carbon is sequestered in the wood or mechanistic insights on the physiological processes driving woody net primary production. Moreover, external measurements of tree girth are not only recording xylem tissue formation, but are also influenced by the formation and degradation of bark tissues and stem water status ${ }^{15,16}$. A detailed, process-oriented understanding of woody biomass production is therefore a timely and necessary endeavour to improve our knowledge of terrestrial carbon cycle and its interactions with climate.

Here, we investigate the seasonal dynamics and climatic sensitivity of tree radial growth and woody biomass production by performing 3 years of weekly observations of wood formation for three temperate mixed coniferous forests (silver fir, Norway spruce and Scots pine) located in the Vosges Mountains in northeast France. Detailed measurements of the developing wood and resulting tree-ring structure in concert with accurate computation of cellular development kinetics ${ }^{17}$ allow us, for the first time, to quantify the magnitude and dynamics of carbon sequestration into tree stem on intra-seasonal time scales (Supplementary Fig. 1). Notably, by compiling and analysing more general data spanning the Northern Hemisphere on the timing of xylem tissue formation, we demonstrate the consistency of key findings across the major coniferous forest biomes.

We find that wood formation processes spanned nearly 7 months, from mid-April to early November, in the Vosges Mountains (Fig. 1). This period encompasses the production and differentiation of the new xylem cells through cambial cell divisions, cell enlargement and cell wall thickening (including secondary wall formation and lignification). The complex integration of these cellular processes results in both xylem size increase and woody biomass production. The rates of xylem cell production and xylem size increase peaked at the end of May, with xylem cell production also showing a secondary mid-summer local maximum (Fig. 1b). In these consistently well-watered forests, the dynamics and magnitude of xylem size increase generally matched the seasonal changes of stem girth measured by dendrometers on the same trees (Fig. 1a,c; Supplementary Fig. 2). Enlargement of the newly differentiating xylem cells was responsible for $80 \%$ of the xylem size increase, with the remaining $20 \%$ attributable to the production of the new xylem cells (Fig. 1c). Consequently, the rate of xylem size increase peaked when most cells were in the enlarging phase, which furthermore coincided with development of large earlywood cells. In contrast, woody biomass production was mostly (90\%) driven 

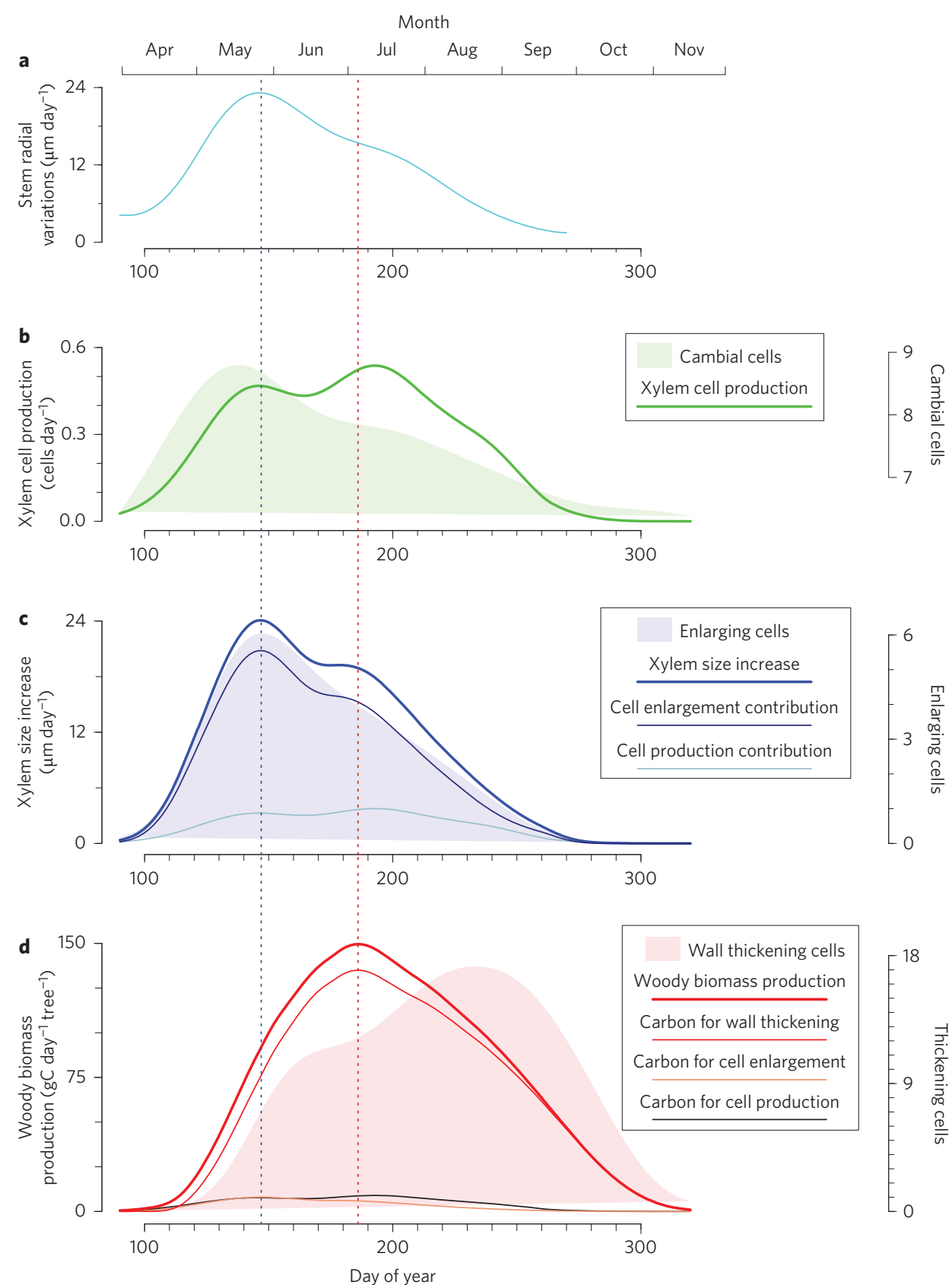

Figure 1 | Seasonal dynamics of stem-girth increase, xylem size increase and woody biomass production. $\mathbf{a}$, Stem-external radial variations. $\mathbf{b}$, Rate of xylem cell production through cambial cell divisions and number of cambial cells (shading). c, Rate of xylem size increase, with isolated contributions of cell production and cell enlargement, together with the number of enlarging cells (shading). d, Rate of woody biomass production, which sums the carbon sequestered by wall thickening plus that from cell enlargement and cell production. Shading is number of wall thickening cells. Vertical blue and red dashed lines indicate time of maximal rates of xylem size increase and woody biomass production. Data are means for the three northeast France sites (Vosges mountains), with the three species (silver fir, Norway spruce and Scots pine) monitored during three years (2007-2009).

by cell wall thickening and followed a symmetric bell-shaped curve peaking in early July (Fig. 1d). Contrary to long-held hypotheses that the maximal rate of woody biomass production occurs during latewood development ${ }^{17}$, we find this takes place during the formation of the transition wood (between earlywood and latewood), before the differentiation of the small and thick-walled latewood cells had even begun.

We observe a shift of 40 days between the maximal rates of xylem size increase and woody biomass production (Fig. 1c,d). In midSeptember, when xylem stopped increasing in size, woody biomass production was still at almost $50 \%$ of its maximal rate. Woody biomass production requires on average 26 days to reach the same relative advancement as xylem size increase (Fig. 2a). In this sense, $90 \%$ of the final tree-ring width was completed by early August, whereas only $70 \%$ of the final amount of carbon was permanently fixed into xylem cell walls.

The asynchrony we observe at the tissue level between xylem size increase and woody biomass production is the complex integral of cellular characteristics, developmental phases and kinetics, and the ever-changing proportion of cells in these phases during tree-ring formation. In fact, growth in size and biomass are dissociated even at the cellular level. Immediately after its birth, a maturing xylem cell enlarges radially, stretching its thin primary wall without incorporating much carbon. Only once the final cell size 
a

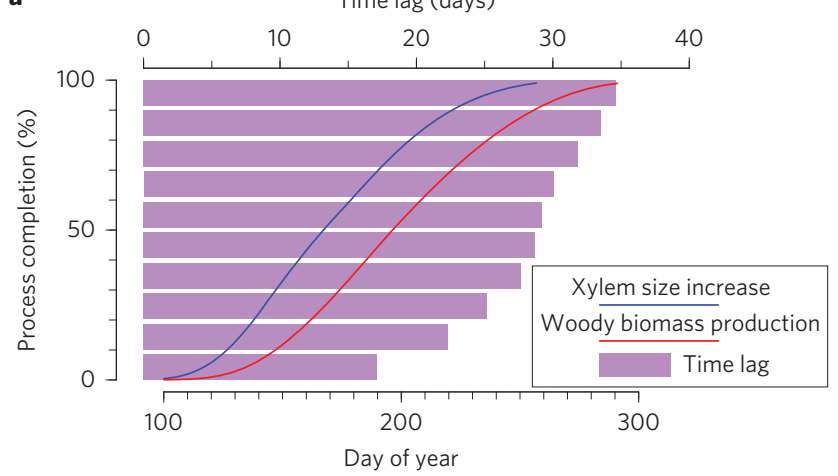

b Apr May Jun Jul Aug Sep Oct
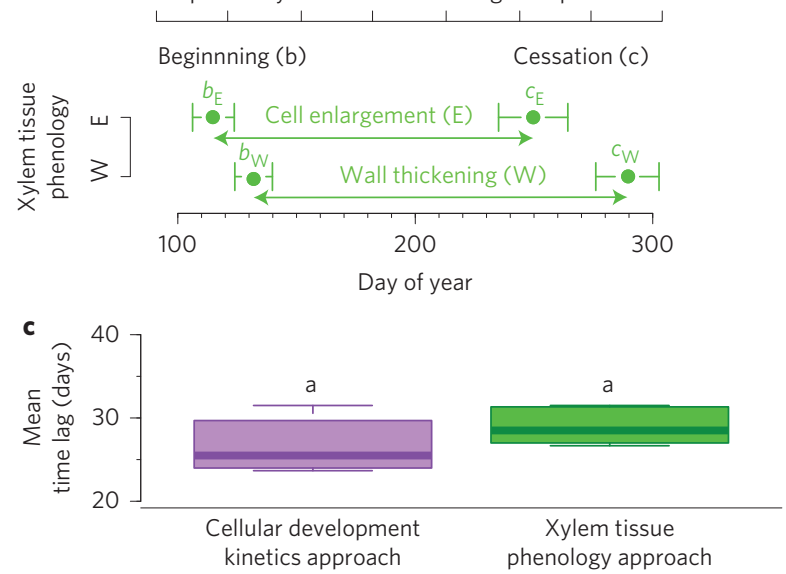

Figure 2 | Asynchrony of xylem size increase and woody biomass production, along with xylem phenology. a, Time lag between seasonal dynamics of xylem size increase and woody biomass production when both processes are expressed in percentage of completion. $\mathbf{b}$, Critical dates of the phenology of xylem tissue formation used to estimate the mean time lag between xylem size increase and woody biomass production (mean time lag $=\left(\left(b_{\mathrm{W}}-b_{\mathrm{E}}\right)+\left(c_{\mathrm{W}}-c_{\mathrm{E}}\right)\right) / 2$, see Methods). $\mathbf{c}$, Similarity of results for mean time lag between xylem size increase and woody biomass production as derived from the integration of the kinetics of each developing xylem cell and from the assessment of the phenology of xylem tissue formation. In $\mathbf{a}, \mathbf{b}$, data represent the means (with associated standard deviations in b) for northeast France (over sites, species and years). In c, boxplots represent nine values of mean time lag (one value per site and year). Different letters above boxes indicate significant differences $(P<0.05$, Wilcoxon rank-sum test, $n=18$ ).

is reached, the cell wall thickening starts and sequesters the majority of carbon fixed in the cell structure. Moreover, although cell enlargement is principally a rapid physical process, wall thickening involves time-consuming assembly of complex material ${ }^{17}$. This difference systematically increases during the growing season, as the wide thin-walled earlywood cells require 12 days for enlargement and 22 days for wall thickening, whereas the narrow thickwalled latewood cells require 6 and 50 days, respectively ${ }^{17}$. All these factors explain why growth in biomass lags behind growth in size at our sites in France.

To assess if the time lag between xylem size increase and woody biomass production is common to diverse coniferous forest biomes, we compiled phenological observations of xylem tissue formation from a network of 51 sites across the Northern Hemisphere (Supplementary Table 1). Although detailed cellular development kinetics are not available for these sites, our data from northeast France show that the periods devoted to xylem size increase,

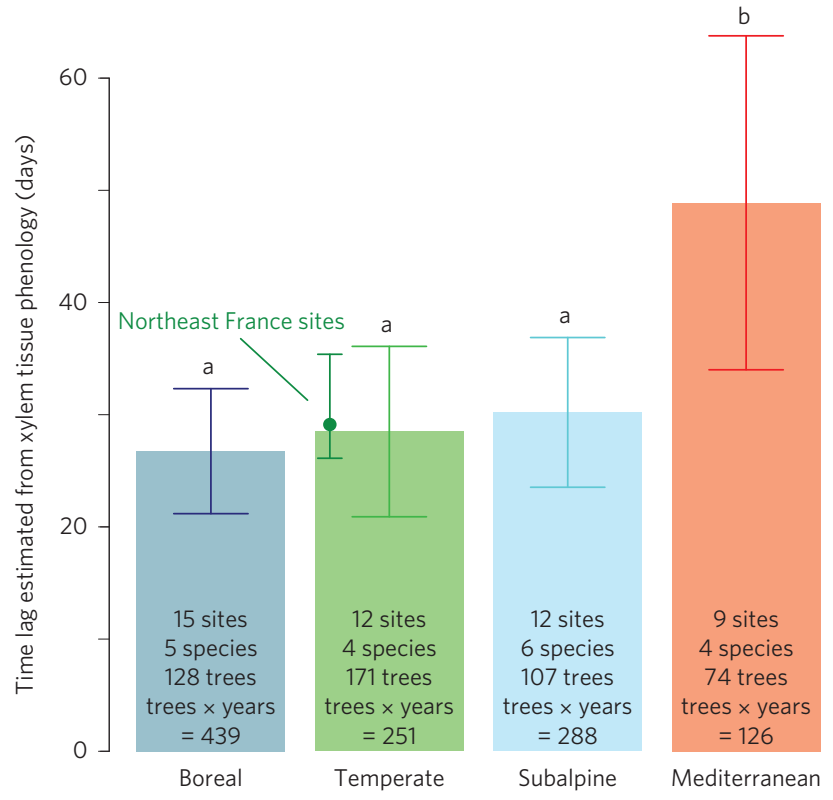

Figure 3 | Delay between xylem size increase and woody biomass production for the major coniferous forest biomes of the Northern Hemisphere. Different letters above bars indicate significant differences ( $P<0.05$, one-way analysis of variance with Tukey post-hoc test, $n=213$ ). See Supplementary Table 1 for sites.

woody biomass production and the mean time lag between these two processes can be reasonably estimated by using the available observations on the timing of xylem tissue formation (that is beginning and cessation of cell enlargement and cell wall thickening periods) (Fig. 2b,c). Accordingly, we observe approximately 1 -month time lags for boreal ( $27 \pm 6$ days), temperate $(28 \pm 8$ days) and subalpine forests ( $30 \pm 7$ days), and nearly $50 \%$ longer for Mediterranean forests ( $49 \pm 15$ days) (Fig. 3). The longer and more variable time lags observed in Mediterranean regions may be linked to longer growing seasons (related to favourable thermal conditions) and more complex growing patterns (related to summer water stress) that characterize such environments ${ }^{18}$. These analyses allow us to conclude that the delay between xylem size increase and woody biomass production quantified for the French sites is common to the Northern Hemisphere coniferous forests.

The widespread asynchrony between xylem size increase and woody biomass production suggests a different sensitivity of these processes to climatic factors. We can test these notions by returning to the comprehensive French dataset. Cross-correlation and regression analysis between the seasonal course of the environmental conditions (day length, light radiation intensity, soil water content, temperature) and the intra-annual dynamics of xylem size increase and woody biomass production reveal consistent synchronizations for all three species: the intra-annual dynamics of xylem size increase had the strongest relationship with photoperiod (Fig. 4a,b), whereas woody biomass production was tightly coupled with the seasonal temperature course (Fig. 4c,d).

These results offer new insights into the adaptation of plants to their environment. Photoperiod has long been regarded as a stable indicator of the time of the year that controls many developmental responses in plants ${ }^{19}$. In extra-tropical trees, the onset of xylem production is controlled by temperature ${ }^{20,21}$, but our results support the idea that its dynamics then synchronizes with the photoperiod cycle to ensure cells will have sufficient time to finish their differentiation before winter ${ }^{22}$. The synchronization we find between woody biomass production and the seasonal cycle of 

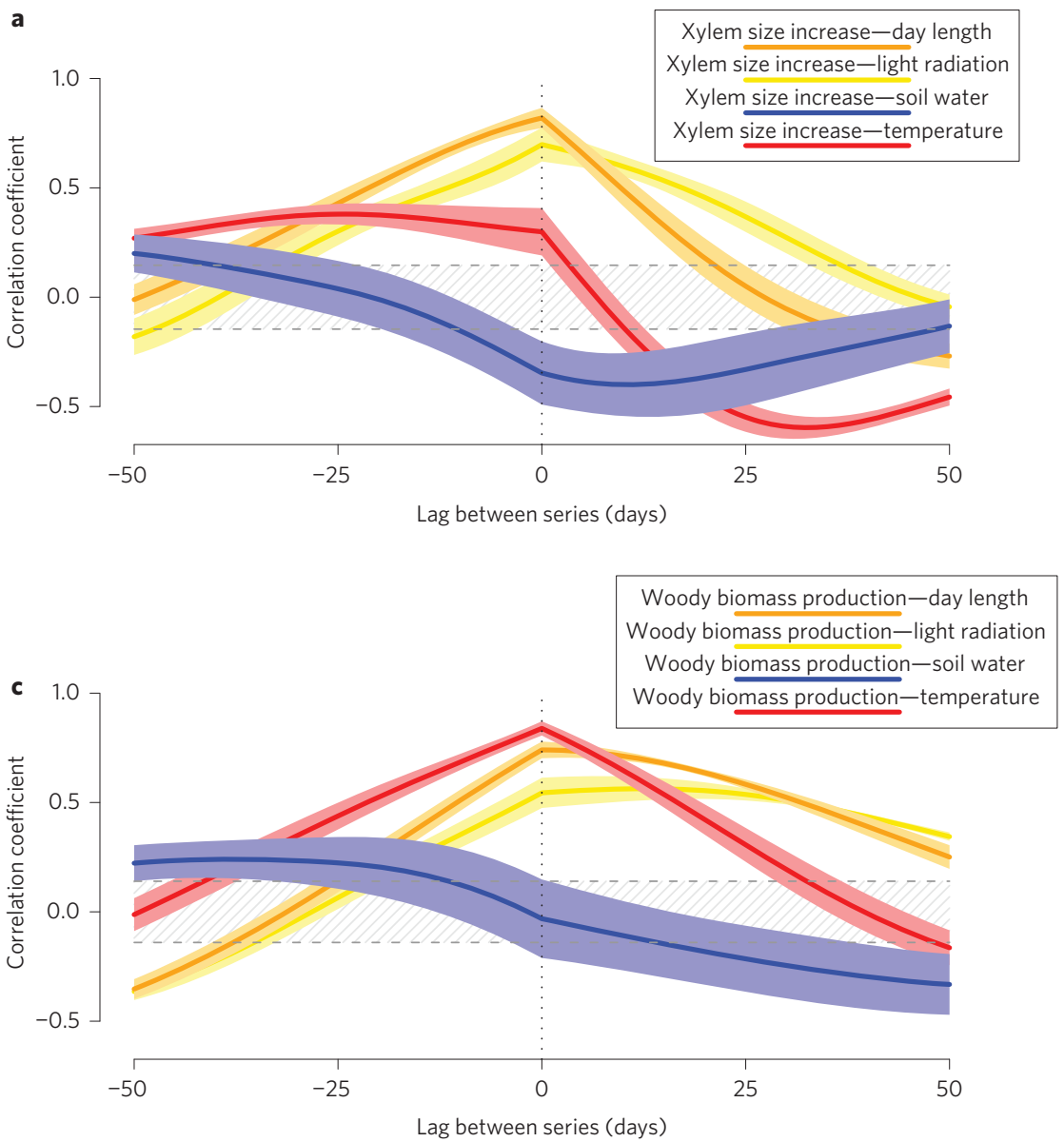

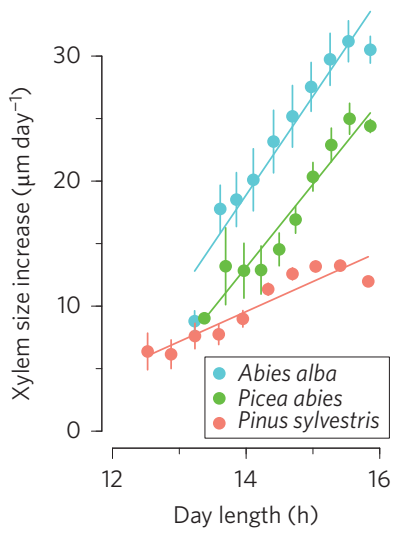

Figure 4 | Coordination of xylem size increase and woody biomass production with environmental factors. a, Cross-correlation between the seasonal dynamics of xylem size increase and environmental factors. b. Relationships between the seasonal dynamics of xylem size increase and day length. c, Cross-correlation between the seasonal dynamics of woody biomass production and environmental factors. $\mathbf{d}$, Relationships between the seasonal dynamics of woody biomass production and temperature. Data are means for the three northeast France sites (Vosges mountains), with the three species (silver fir, Norway spruce and Scots pine) monitored during 3 years (2007-2009). In a,c, the different curves represent the mean correlation coefficients between the different couples of series according to a time lag applied to one of the two considered series (see Methods for details on cross-correlation). Shaded area around lines represents 95\% confidence interval. Hatched area represents coefficient values above significance level ( $P>0.05$ ). For b,d, each point represents the mean value of the process rate within a class of the environmental factor, and vertical bars represent $95 \%$ confidence interval.

temperatures is less well understood, but could be linked to the strong metabolic activity that supports cell wall thickening ${ }^{23,24}$. Cell wall lignification in particular has been suggested to be the most temperature-sensitive process involved in tree carbon balance ${ }^{25}$. Yet, caution is warranted in extrapolating these climatic associations from northeast France, a region characterized both by sufficient precipitation and strong seasonal changes in light and temperature, to other regions. While we expect comparable findings for similar biomes, a higher sensitivity to water availability may be expected in environments characterized by strong and regular mid-season soil water deficits, as in the Mediterranean.

The time lag and different climatic associations found for xylem size increase and woody biomass production are in agreement with observations made by dendroclimatologists that cell size and cell wall thickness chronologies (linked to xylem size increase and woody biomass production, respectively) convey climatic signals from different parts of the season ${ }^{26}$. Most generally, our findings contribute to the explanation of why different climatic fingerprints are widely observed in tree-ring width and maximum wood density ${ }^{27,28}$. Finally, since global change involves shift in the seasonal climatic cycles $^{7}$, the phasing of xylem size increase and woody biomass production might change. With projections of continuing climate change, all of these considerations suggest profound impacts on tree-ring structure ${ }^{17}$, associated functional trade-offs ${ }^{29}$, and carbon fluxes in forest ecosystems $s^{3,6}$.

Our results question the inter-changeable usage of size growth and biomass growth at intra-annual scales. Classically, in biomass studies 'growth' is used to indifferently define an irreversible increase in size or mass due to metabolic process ${ }^{3-6,28}$. As mature trees cannot be weighed easily, mass gain is usually assessed from stem diameter and/or tree height measurements via allometric equations $^{3-6}$. Increases in size and in biomass are actually well related in space $^{28}$, and at inter-annual time scales ${ }^{3,28}$, which has further fuelled the idea that seasonal dynamics of tree-girth changes equated directly woody biomass production ${ }^{3-6}$.

However, we demonstrate that, at the intra-annual scale, woody biomass production lags significantly behind xylem size increase, suggesting challenges to properly infer the seasonal dynamics of woody net primary production from external measurements of stem size change. At a minimum, this time lag needs to be taken into account, but estimates are further complicated by other factors such as changes in stem water status that cause reversible stem size fluctuations ${ }^{15,16}$. Moreover, we hypothesize that reduced agreement between cellular observations and external measurements of xylem production would be found at sites where the proportion of bark to the annual xylem increment is greater or where 
water storage undergoes stronger seasonal fluctuations. The revealed time lag also provides a mechanistic basis to understand the discrepancies observed between eddy covariance and tree size data ${ }^{5,14}$. It notably contributes to explanations for the lack of relationships between net ecosystem productivity and tree size changes at short time scales ${ }^{5,15}$, and the positive forest carbon uptake when stemgirth increase is over in autumn ${ }^{14}$.

Finally, our work helps to better understand the seasonal balance of terrestrial carbon, providing insights and methods to link forest-atmosphere exchanges and woody carbon sequestration at intra-seasonal time scales. Modelling the dynamics of the processes that drive carbon fluxes in different ecosystem components is a key issue, especially for assessing how climate change impacts these ecosystem ${ }^{30}$. Our detailed mechanistic representation of when and how carbon is sequestered into the wood during the growing season provides crucial information on a major carbon flux and storage component of forest ecosystems. Such information is essential for further developing the process-based biosphere models to better constrain modern carbon budgets and to predict future carbon-climate interactions ${ }^{30}$.

\section{Methods}

Study sites for detailed monitoring of wood formation. Three sites were selected in mixed mature temperate forests composed of silver firs (Abies alba Mill.), Norway spruces (Picea abies (L.) Karst.) and Scots pines (Pinus sylvestris L.) in the Vosges Mountains (northeast France). The three sites were spread on a north-south axis of about $15 \mathrm{~km}$ and were named according to the closest town: Walscheid (370 m ASL, $\left.48^{\circ} 38^{\prime} \mathrm{N}, 7^{\circ} 09^{\prime} \mathrm{E}\right)$, Abreschviller ( $430 \mathrm{~m}$ ASL, $\left.48^{\circ} 36^{\prime} \mathrm{N}, 7^{\circ} 08^{\prime} \mathrm{E}\right)$ and Grandfontaine (650 $\mathrm{m} \mathrm{ASL}, 48^{\circ} 28^{\prime} \mathrm{N}, 7^{\circ} 08^{\prime} \mathrm{E}$ ). On each site, pits were dug to depict soil profiles, and complete inventories were built to describe stand structure. Based on these inventories, five dominant and healthy trees of silvers fir, Norway spruce and Scots pine were selected on each site, for a total of 45 studied trees ( 5 trees $\times 3$ species $\times 3$ sites) for 3 years (2007-2009) of wood formation monitoring (Supplementary Table 2).

Dendrometer and meteorological data. Manual band dendrometers (DB-20, EMS Brno, Czech Republic) were installed at breast height in March 2007 on the stem of all selected trees, after the removal of most part of the dead bark, and were read weekly thereafter to monitor stem circumference variations. Changes in stem girth measured by band dendrometers were transformed into stem radial variations assuming a circular cross-section of the stem.

Daily meteorological data (temperature, precipitation, cumulative global radiation, wind speed and relative air humidity) of the monitoring period were gathered from three meteorological stations, each of them located less than $2 \mathrm{~km}$ from the corresponding site.

Modelling soil water balance and characterizing the seasonality of environmenta factors. We used a forest water balance model to assess the daily water balance of the three studied stands during the 3 monitoring years (Supplementary Methods). Daily water balance and meteorological data (temperature and light radiation) were then smoothed using generalized additive models (GAMs) to obtain representative seasonal trends of climatic conditions.

High-resolution quantification of wood formation dynamics at northeast France sites. To assess the seasonal dynamics of wood formation, small wood samples (microcores) were collected weekly during 3 years (2007-2009) on the stem of the selected 45 mature trees grown in three sites in northeast France. Microcores were prepared in the laboratory, after what anatomical sections were cut, stained and analysed using an optical microscope to track wood formation processes. On the anatomical sections, we counted the cells in the different zones of differentiation along the forming tree ring: cambial cells, enlarging cells, wall thickening cells and mature cells. GAMs were then applied on the cell count data and used in concert with detailed measurements of cell anatomy to compute the cellular development kinetics (timing, duration and rate of cell enlargement and wall thickening). These detailed quantifications of the cellular development kinetics were integrated over the course of the season to compute the rate of xylem size increase and the rate of woody biomass production. The latter was expressed in grams of carbon per tree based on parameters such as carbon content in wood, density of the cell walls, tree height and stem basal diameter. Full details on the sampling procedure, on the criteria used to distinguish and count the cells in the different developing zones along the tree ring, on the application of GAMs to the cell counts, on the anatomical measurements and on the calculation of the rates of xylem size increase and woody biomass production are given in the Supplementary Methods.

Estimate of the timing of growth processes in Northern Hemisphere forest biomes. In addition to the detailed cellular based quantifications performed for the studied sites in northeast France, we built a global dataset of more widely available phenological observations of xylem tissue formation to estimate the timing of xylem size increase and woody biomass production in diverse coniferous forest biomes of the Northern Hemisphere (Supplementary Table 1). For that, we considered the phenology of the periods of cell enlargement and cell wall thickening as proxies for the timing of xylem size increase and woody biomass production, respectively. The mean time lag between xylem size increase and woody biomass production was assessed from the differences observed between the beginnings and the cessations of the periods of cell enlargement and cell wall thickening (see Supplementary Methods for further explanations)

Assessment of the phasing between the seasonal dynamics of growth processes and environmental factors. To assess the synchronization between xylem size increase, carbon sequestration and environmental factors during the season, crosscorrelations were performed between the different time series. We further assessed dependency of xylem size increase and woody biomass production with the environmental factors using linear models. Additional details on these analyses are provided in the Supplementary Methods.

Received 12 June 2015; accepted 25 September 2015; published 26 October 2015

\section{References}

1. Lal, R. Sequestration of atmospheric $\mathrm{CO}_{2}$ in global carbon pools. Energy Environ. Sci. 1, 86-100 (2008).

2. Pan, Y. et al. A large and persistent carbon sink in the world's forests. Science 333, 988-993 (2011).

3. Barford, C. C. et al. Factors controlling long-and short-term sequestration of atmospheric $\mathrm{CO}_{2}$ in a mid-latitude forest. Science 294, 1688-1691 (2001).

4. Etzold, S. et al. The carbon balance of two contrasting mountain forest ecosystems in Switzerland: similar annual trends, but seasonal differences. Ecosystems 14, 1289-1309 (2011).

5. Gough, C., Vogel, C., Schmid, H., Su, H.-B. \& Curtis, P. Multi-year convergence of biometric and meteorological estimates of forest carbon storage. Agr. Forest Meteorol. 148, 158-170 (2008).

6. Doughty, C. E. et al. Drought impact on forest carbon dynamics and fluxes in Amazonia. Nature 519, 78-82 (2015).

7. Stine, A. R., Huybers, P. \& Fung, I. Y. Changes in the phase of the annual cycle of surface temperature. Nature 457, 435-440 (2009).

8. Graven, H. et al. Enhanced seasonal exchange of $\mathrm{CO}_{2}$ by northern ecosystems since 1960. Science 341, 1085-1089 (2013).

9. Moss, R. H. et al. The next generation of scenarios for climate change research and assessment. Nature 463, 747-756 (2010).

10. Baldocchi, D. D. Assessing the eddy covariance technique for evaluating carbon dioxide exchange rates of ecosystems: past, present and future. Global Change Biol. 9, 479-492 (2003).

11. Davidson, E. et al. Belowground carbon allocation in forests estimated from litterfall and IRGA-based soil respiration measurements. Agr. Forest Meteorol. 113, 39-51 (2002).

12. Richardson, A. D., Braswell, B. H., Hollinger, D. Y., Jenkins, J. P. \& Ollinger, S. V. Near-surface remote sensing of spatial and temporal variation in canopy phenology. Ecol. Appl. 19, 1417-1428 (2009).

13. Dong, J. et al. Remote sensing estimates of boreal and temperate forest woody biomass: carbon pools, sources, and sinks. Remote Sens. Environ. 84, 393-410 (2003).

14. Granier, A., Bréda, N., Longdoz, B., Gross, P. \& Ngao, J. Ten years of fluxes and stand growth in a young beech forest at Hesse, North-eastern France. Ann. For. Sci. 65, 704-716 (2008).

15. Zweifel, R. et al. Link between continuous stem radius changes and net ecosystem productivity of a subalpine Norway spruce forest in the Swiss Alps. New Phytol. 187, 819-830 (2010).

16. King, G., Fonti, P., Nievergelt, D., Büntgen, U. \& Frank, D. Climatic drivers of hourly to yearly tree radius variations along a $6{ }^{\circ} \mathrm{C}$ natural warming gradient. Agr. Forest. Meteorol. 168, 36-46 (2013).

17. Cuny, H. E., Rathgeber, C. B. K., Frank, D., Fonti, P. \& Fournier, M. Kinetics of tracheid development explain conifer tree-ring structure. New Phytol. 203, 1231-1241 (2014)

18. Camarero, J. J., Olano, J. M. \& Parras, A. Plastic bimodal xylogenesis in conifers from continental Mediterranean climates. New Phytol. 185, 471-480 (2010).

19. Jackson, S. D. Plant responses to photoperiod. New Phytol. 181, 517-531 (2009).

20. Rossi, S. et al. Critical temperatures for xylogenesis in conifers of cold climates Global Ecol. Biogeogr. 17, 696-707 (2008).

21. Oribe, Y., Funada, R., Shibagaki, M. \& Kubo, T. Cambial reactivation in locally heated stems of the evergreen conifer Abies sachalinensis (Schmidt) Masters. Planta 212, 684-691 (2001).

22. Rossi, S. et al. Conifers in cold environments synchronize maximum growth rate of tree-ring formation with day length. New Phytol. 170, 301-310 (2006).

23. Simard, S. et al. Intra-annual dynamics of non-structural carbohydrates in the cambium of mature conifer trees reflects radial growth demands. Tree Physiol. 33, 913-923 (2013). 
24. Körner, C. Carbon limitation in trees. J. Ecol. 91, 4-17 (2003).

25. Donaldson, L. A. Lignification and lignin topochemistry-an ultrastructural view. Phytochemistry 57, 859-873 (2001).

26. Fonti, P. et al. Temperature-induced responses of xylem structure of Larix sibirica (Pinaceae) from the Russian Altay. Am. J. Bot. 100, 1332-1343 (2013).

27. Briffa, K. et al. Tree-ring width and density data around the Northern Hemisphere: Part 1, local and regional climate signals. Holocene 12, 737 (2002)

28. Babst, F. et al. Above-ground woody carbon sequestration measured from tree rings is coherent with net ecosystem productivity at five eddy-covariance sites. New Phytol. 201, 1289-1303 (2014).

29. Lachenbruch, B. \& McCulloh, K. A. Traits, properties, and performance: how woody plants combine hydraulic and mechanical functions in a cell, tissue, or whole plant. New Phytol. 204, 747-764 (2014).

30. Medvigy, D., Wofsy, S., Munger, J., Hollinger, D. \& Moorcroft, P. Mechanistic scaling of ecosystem function and dynamics in space and time: Ecosystem Demography model version 2. J. Geophys. Res. 114, G01002 (2009).

\section{Acknowledgements}

H.E.C. and C.B.K.R. thank E. Cornu, E. Farré, C. Freyburger, P. Gelhaye and A. Mercanti for fieldwork at the French sites; M. Harroué for sample preparation in the laboratory; B. Longdoz of the forest ecology and ecophysiology (EEF) team of the French nationa institute for agronomy research (INRA), and the association for the study and monitoring of air pollution in Alsace (ASPA), for the meteorological data. M. Nicolas of the French permanent plot network for the monitoring of forest ecosystems (RENECOFOR) for the meteorological data and the description of the soil profiles. L. Kulmala and J. Guiot for comments on an early version of this manuscript. H.M., T.J. and P.N. thank T. Kalliokosk for the Solböle data. J.G.H. thanks L.H. Zhai for laboratory work and Y. Bergeron for project supervision. H.V. and V.G. thank J. Hacurová and G. Vichrová for laboratory work. H.E.C was supported by a grant overseen by the French National Research Agency (ANR) as part of the 'Investissements d'Avenir' programme (ANR-11-LABX-0002-01, Lab of Excellence ARBRE). D.F. and P.F. acknowledge the SNF (INTEGRAL-121859 and LOTFOR-150205), and the WSL SwissTree project. J.G.H. was funded by 100 Talents Program of the Chinese Academy of Sciences (Y421081001). I.S. and A.G. were funded by the Austrian Science Fund (FWF P19563-B16 and P22280-B16). H.M., T.J. and P.N. were supported by grants from the Academy of Finland (Nos. 250299, 257641 and 265504). P.P., J.G. and K.C. were supported by the Slovenian Research Agency, young researchers' programme and programmes P4-0015 and P4-0107. H.V. and V.G. were supported by the European Social Fund and the state budget of the Czech Republic, Project Indicators of trees vitality Reg. No. CZ.1.07/2.3.00/20.0265. M.V.B. and A.V.K. were supported by Russian Science Foundation project 14-14-00295. The Canadian boreal forest dataset collected by H.M, C.K, A.D. and S.R. were supported by the CRSNG, the FRQNT, the FCI and the Consortium de Recherche sur la Forêt Boréale Commerciale. S.R. was also supported by the CAS President's International Fellowship Initiative (GRANT No. 2015VBB032). The dataset on xylem phenology was generated by the GLOBOXYLO initiative (http://www6.nancy.inra.fr/foretbois-lerfob_eng/Projects/Current/GLOBOXYLO), which was developed in the framework of the FPS COST Action STReESS (FP1106)

\section{Author contributions}

C.B.K.R. conceived the French experimental device and compiled the Northern Hemisphere dataset on xylem phenology. H.E.C. created the data for the French sites, performed the research and analysed the data with the help of C.B.K.R. H.E.C. wrote the manuscript and prepared the figures, with the assistance of C.B.K.R., D.F., P.F. and M.F. All the authors contributed with xylem phenology data and discussed the manuscript.

\section{Additional information}

Supplementary information is available online. Reprints and permissions information is available online at www.nature.com/reprints. Correspondence and requests for materials should be addressed to H.E.C.

\section{Competing interests}

The authors declare no competing financial interests.

Henri E. Cuny, ${ }^{1,2} 3 *$, Cyrille B. K. Rathgeber, ${ }^{1,2}$, David Frank ${ }^{3,4}$, Patrick Fonti ${ }^{3}$, Harri Mäkinen ${ }^{5}$, Peter Prislan ${ }^{6}$, Sergio Rossi ${ }^{7,8}$, Edurne Martinez del Castillo9 , Filipe Campelo10, Hanuš Vavrčík¹, Jesus Julio Camarero ${ }^{12}$, Marina V. Bryukhanova13,14, Tuula Jyske ${ }^{5}$, Jožica Gričar ${ }^{6}$, Vladimír Gryc ${ }^{11}$, Martin De Luis ${ }^{9}$, Joana Vieira ${ }^{10}$, Katarina Čufar ${ }^{15}$, Alexander V. Kirdyanov³,14, Walter Oberhuber ${ }^{16}$, Vaclav Treml17, Jian-Guo Huang ${ }^{8}$, Xiaoxia Li ${ }^{18}$, Irene Swidrak ${ }^{16}$, Annie Deslauriers ${ }^{7}$, Eryuan Liang ${ }^{18}$, Pekka Nöjd ${ }^{5}$, Andreas Gruber ${ }^{16}$, Cristina Nabais ${ }^{10}$, Hubert Morin7, Cornelia Krause ${ }^{7}$, Gregory King ${ }^{19}$ and Meriem Fournier ${ }^{1,2}$

'INRA, UMR 1092 LERFOB, Champenoux F-54280, France. ${ }^{2}$ AgroParisTech, UMR 1092 LERFOB, Nancy F-54000, France. ${ }^{3}$ Swiss Federal Research Institute WSL, Birmensdorf $\mathrm{CH}-8903$, Switzerland. ${ }^{4}$ Oeschger Centre for Climate Change Research, Bern $\mathrm{CH}-3012$, Switzerland. ${ }^{5}$ Natural Resources Institute Finland, PO Box 18, Vantaa 01301, Finland. 'Slovenian Forestry Institute, Vecna pot 2, Ljubljana 1000, Slovenia. 'Université du Québec à Chicoutimi, Chicoutimi, QC G7H 2B1, Canada. ${ }^{8}$ Key Laboratory of Vegetation Restoration and Management of Degraded Ecosystems, Provincial Key Laboratory of Applied Botany South China Botanical Garden, Chinese Academy of Sciences, Guangzhou 510650, China. ${ }^{9}$ Department of Geography and Regional Planning, Environmental Science Institute (IUCA), University of Zaragoza, C/Pedro Cerbuna 12, Zaragoza 50009, Spain. ${ }^{10}$ Centre for Functional Ecology, Department of Life Sciences, University of Coimbra, Calçada Martim de Freitas, Coimbra 3000-456, Portugal. "Faculty of Forestry and Wood Technology, Department of Wood Science, Mendel University in Brno, Zemědělská 3, Brno 613 00, Czech Republic. ${ }^{12}$ Instituto Pirenaico de Ecología (IPE-CSIC), Avda. Montañana 1005, Zaragoza 50192, Spain. ${ }^{13}$ V.N. Sukachev Institute of Forest, SB RAS, Krasnoyarsk 660036, Russia. ${ }^{14}$ Siberian Federal University, 660041 Krasnoyarsk, Russia. ${ }^{15}$ Biotechnical Faculty, University of Ljubljana, Jamnikarjeva 101, Ljubljana 1000, Slovenia. ${ }^{16}$ University of Innsbruck, Institute of Botany, Sternwartestrasse 15, Innsbruck 6020, Austria. ${ }^{17}$ Faculty of Science, Charles University in Prague, Prague CZ-12843, Czech Republic. ${ }^{18}$ Key Laboratory of Tibetan Environment Changes and Land Surface Processes and Key Laboratory of Alpine Ecology and Biodiversity, Institute of Tibetan Plateau Research, Chinese Academy of Sciences, Beijing 100101, China. ${ }^{19}$ Department of Geography, Queen's University, Kingston, Canada. *e-mail: henri.cuny@wsl.ch 